\title{
Methyl Epijasmonate in the Essential Oil of Tea
}

\author{
Akio Kobayashi, Miho Kawamura, Yuuko Yamamoto, \\ Kei Shimizu, Kikue Kubota and Tei Yamanishi \\ Laboratory of Food Chemistry, Ochanomizu University, \\ 2-1-1, Ohtsuka, Bunkyo-ku, Tokyo 112, Japan
}

Received April 11, 1988

\begin{abstract}
Methyl epijasmonate has a 400 times stronger aroma than methyl jasmonate, which is known to be one of the key compounds in the aroma of tea, and the former is easily isomerized on heating. Reinvestigation of the separation and identification of tea aroma compounds indicated that steam distillation should be performed under reduced pressure, and that the gas chromatographic conditions should be controlled at below $170^{\circ} \mathrm{C}$ using an open tubular column coated with a nonpolar liquid phase to avoid the isomerization or decomposition of methyl epijasmonate. Under the conditions, ten types of teas were analyzed, and methyl epijasmonate was shown to contribute to the aroma of tea, particularly, to that of Chinese semi-fermented teas.
\end{abstract}

In our preceding chemical studies on Chinese oolong and pouchong teas, ${ }^{1}{ }^{\sim 3}$ methyl jasmonate (I) was identified as one of the main components contributing to the aroma of semi-fermented teas due to its characteristic odor and low threshold value, in spite of its relatively low concentration in the aroma concentrate. However, Acree et $a .^{+1}$ have pointed out, on the basis of the results of their chemical study on the sex pheromone of the oriental fruit moth Grapholitha molesta, that the odor of methyl epijasmonate (II) is 400 times stronger than that of I. They also claimed that the aroma of $\mathbf{I}$ has been mistaken for that of II, which is present in I in a trace amount, because unstable II would have been easily isomerized to I on heating during its separation and identification. Therefore, it became necessary to reinvestigate our experimental conditions for the separation and identification of $\mathbf{I}$ and/or II in the essential oil of tea. This report

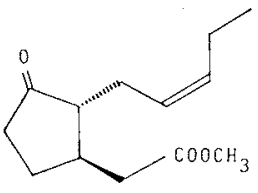

methyl jasmonate (I)

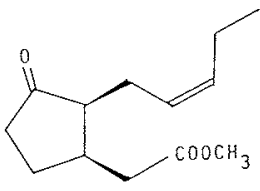

methyl epijasmonate (II) describes selection of the optimal conditions for the preparation of an aroma concentrate from tea and for gas chromatography for the separation of the components in the aroma concentrated without any decomposition or isomerization of II. Under the determined conditions, we also attemped to quantitatively analyse II in various types of tea, and we discuss the contribution of II to the aroma of tea.

\section{MATERIALS AND METHODS}

Materials. Standards I and II were donated by Dr. Warita $^{5}$ of Hasegawa Perfumery Co. Three varieties of commercial oolong tea (Huang Chin Kuei, Tieh Kuan Yin and Sui Hsien, 1987 products) were imported from China. Three varieties of pouchong tea (Chin Hsin Oolong, Wu Yi and Ching Hsin Taipon, 1984 products) were supplied by the Taiwan Tea Experimental Station. The green teas (Okumidori and Yabukita) were produced in Japan in 1987, and the black teas examined were Uva and Nilgiri Assam teas imported from Sri Lanka in 1987.

Preparation of aroma concentrates.

(a) Simultaneous distillation and extraction (SDE) method. Powdered tea $(50 \mathrm{~g})$ was refluxed with $500 \mathrm{ml}$ of deionized water, and then vapor-phase extraction with dichloromethane $(100 \mathrm{ml})$ in a modified Likens-Nickerson apparatus ${ }^{(6)}$ was performed for $30 \mathrm{~min}$. After drying with 
anhydrous sodium sulfate, the dichloromethane was evaporated at under $40^{\circ} \mathrm{C}$.

(b) Steam distillation under reduced pressure. Using a standard rotary evaporating system, the volatiles were steam distilled from $100 \mathrm{~g}$ of powdered tea with $500 \mathrm{ml}$ of deionized water at under $50^{\circ} \mathrm{C}$. When almost the whole volume of water had been distilled, the same amount of water was added so that the steam distillation could be repeated. Ether extraction of the volatile components from distilled water ( $c a .1 .21$ ) was performed by our previously reported method."

Gas chromatography $(G C)$ and gas chromatography-mass spectrometry (GC-MS).

(a) GC. A Shimadzu GC-7A gas chromatograph equipped with a flame ionization detector and a Shimadzu CR-3A data processing system was used. The GC conditions were as follows: column, fused silica wall coated open tubular column of $0.25 \mathrm{~mm}$ i.d. $\times 50 \mathrm{~m}$; $\mathrm{N}_{2}$ carrier gas flow rate, $1.2 \mathrm{ml} / \mathrm{min}$; and split ratio, $30: 1$. The oven temperature was held at $60^{\circ} \mathrm{C}$ for $4 \mathrm{~min}$ and then increased to $180^{\circ} \mathrm{C}$ at $2^{\circ} \mathrm{C} / \mathrm{min}$. The injection temperature was $170^{\circ} \mathrm{C}$.

(b) GC-MS. A Hewlett-Packard-5790 gas chromatograph was combined with a JEOL JMS-DX 300 mass spectrometer, with a JEOL-DA-5000 data processing system. The GC conditions were the same as those in (a) and MS analysis of electron impact (EI) at $70 \mathrm{eV}$ was performed.

\section{RESULTS AND DISCUSSION}

\section{Gas Chromatographic Conditions}

Methyl epijasmonate (II) has already been reported $^{5 \text { ) }}$ to be unstable at temperatures above $180^{\circ} \mathrm{C}$ and to be isomerized to the more stable trans form (I). Therefore, the injection temperature was set at $180^{\circ} \mathrm{C}$. A mixture of equal amounts of standards $\mathbf{I}$ and II was injected into a $\mathrm{GC}$ equipped with an open tubular column that had been coated with a polar stationary liquid phase such as Carbowax 20M or FFAP, which are genearlly used for the separation of a complex aroma concentrate. A broad peak appeared between two other peaks, but the ratio of the peak areas of $\mathbf{I}$ and $\mathbf{I I}$ did not correspond to that of their concentrations in the mixture. It is suggested that decomposition or isomerization of II occurred during the separation in the column. On the other hand, a standard mixture of $I$ and II could be clearly separated on an OV-1 nonpolar liquid phase column, with retention
Table I. EFFect of the InJection Port Temperature on the Gas Chromatographic RATIO OF II TO I

\begin{tabular}{cccc}
\hline $\begin{array}{c}\text { Injection } \\
\text { temperature } \\
\left({ }^{\circ} \mathrm{C}\right)\end{array}$ & \multicolumn{2}{c}{ Peak area $(\%)$} & $\begin{array}{c}\text { Ratio } \\
\text { II/I }{ }^{a} \\
(\%)\end{array}$ \\
\cline { 2 - 3 } 160 & 57.8 & 42.2 & 73.0 \\
170 & 56.3 & 42.6 & 75.7 \\
180 & 59.6 & 39.6 & 66.4 \\
200 & 68.0 & 30.8 & 45.3 \\
220 & 69.5 & 29.2 & 42.0 \\
\hline
\end{tabular}

actual mixing ratio, $75 \%$.

times of $72.8 \mathrm{~min}$ and $76.6 \mathrm{~min}$, respectively. Under these conditions, gas chromatography of a standard mixture $(I: I=4: 3)$ was performed at different injection port temperatures, and the ratios were calculated from the peak areas. As is shown in Table I, the $\mathbf{I I}$ to $\mathbf{I}$ ratio decreased even at $180^{\circ} \mathrm{C}$, and at greater than $180^{\circ} \mathrm{C}$ the loss of II was more significant. Based on these results, we adopted an $\mathrm{OV}-1$ column temperature of under $180^{\circ} \mathrm{C}$ with an injection temperature at $170^{\circ} \mathrm{C}$ for gas chromatographic analysis of natural $\mathbf{I}$ and $\mathbf{I I}$ in tea aroma concentrates.

\section{Preparing Aroma Concentrates from Tea}

The SDE method has been widely used to prepare aroma concentrates of various types of food material because of its ease; however, it must be performed under atmospheric pressure, i.e., with a steam temperature maintained at $100^{\circ} \mathrm{C}$. To compare the thermal effects during the extraction process, the SDE method and steam distillation under reduced pressure (at $c a .10 \sim 15 \mathrm{mmHg}$ ) were performed for the same tea sample, and then the presence of I and II was checked by GC under the conditions already adopted. As the resolution of a non-polar column for high-polar constituents of an aroma concentrate is not as high as that of a polar column, several peaks appeared near the retention times of standards I and II, and it was impossible to unambiguously identify the peaks of I and II among them. Therefore, we performed mass chroma- 


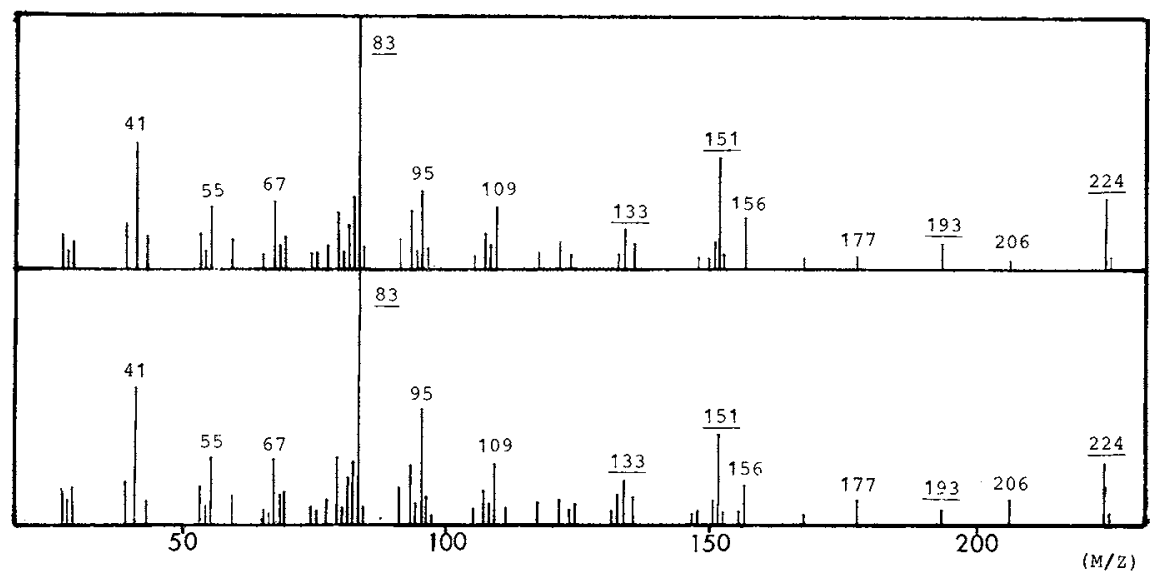

FIG. 1. Mass Spectra of Methyl Jasmonate and Methyl Epijasmonate.

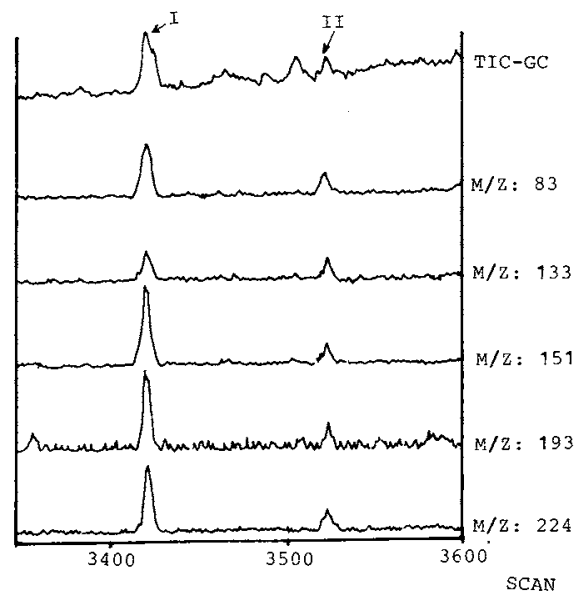

FIG. 2. Mass Chromatograms of Pouchong Tea Aroma Condensates Prepared by Steam Distillation under Reduced Pressure.

TIC-GC, total ion current gas chromatogram.

tography to identify the GC peaks of $\mathbf{I}$ and II. As shown in Fig. 1, the mass spectrograms of I and II were completely the same, from which we could select five fragment peaks, that is, $m / z 224\left(\mathrm{M}^{+}\right), 193,151,133$ and 83, for mass chromatography. For the aroma concentrate obtained by the SDE method, we could find only one peak identifiable as I; however, the steam distillation product under reduced pressure gave two peaks on mass chromatography, as shown in Fig. 2, which were, respectively, identified as those of I and II.

From these results we concluded that iso-
Table II. Yields of Essential Oil from Different Types of TEa on STEam Distillation under REDUCED PRESSURE

\begin{tabular}{lccc}
\hline Sample type & $\begin{array}{c}\text { Sample } \\
\text { amount } \\
(\mathrm{g})\end{array}$ & $\begin{array}{c}\text { Yield } \\
(\mathrm{mg})\end{array}$ & $\begin{array}{c}\text { Present in } \\
\text { the sample } \\
(\mathrm{mg} \%)\end{array}$ \\
\hline Oolong teas & & & \\
$\quad$ Huang Chin Kuei & 100 & 10.8 & 10.8 \\
Tie Kuan Yin & 100 & 10.3 & 10.3 \\
$\quad$ Shui Hsin & 90 & 15.1 & 16.8 \\
Pouchong teas & & & \\
$\quad$ Ching Hsin Oolong & 100 & 14.8 & 14.8 \\
$\quad$ Wu Yi & 100 & 12.8 & 12.8 \\
$\quad$ Ching Hsin Taipon & 100 & 14.7 & 14.7 \\
Green teas & & & \\
$\quad$ Okumidori & 80 & 5.2 & 6.5 \\
$\quad$ Yabukita & 50 & 2.2 & 4.4 \\
Black teas & & & \\
$\quad$ Uva Assam & 100 & 8.3 & 7.4 \\
$\quad$ Nilgiri Assam & 100 & 10.2 & 10.2 \\
\hline
\end{tabular}

merization from II to I occurred during steam distillation on heating at $100^{\circ} \mathrm{C}$; on the other hand, at under $50^{\circ} \mathrm{C}$ we detected a relative amount of II on GC. As we did not have enough standard II to perform the same steam distillation under reduced pressure, we were unable to confirm whether or not II is partly isomerized to $\mathbf{I}$ even at the lower distilling temperature by using the standard mixture as a model system. This problem will be discussed in the following section concerning the contri- 


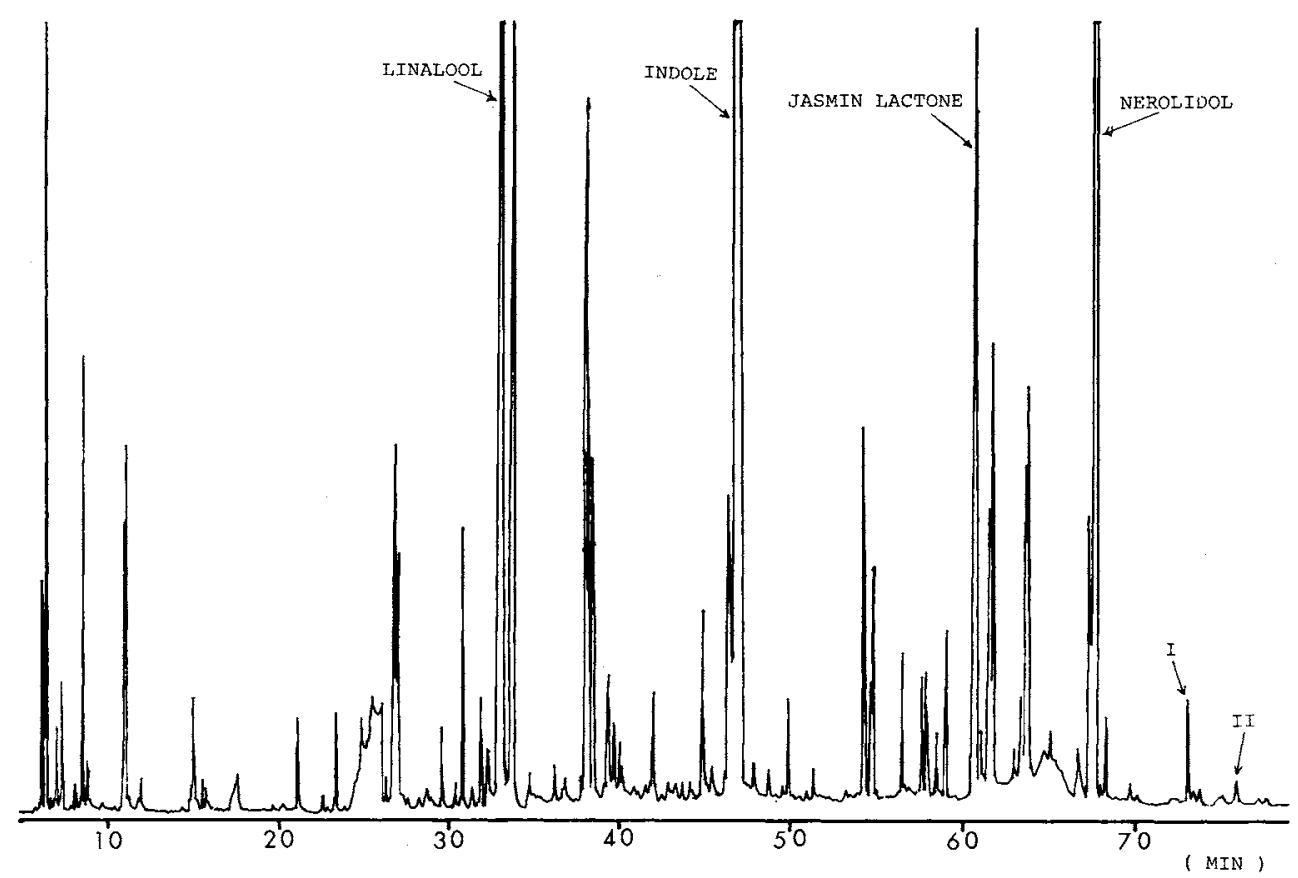

Fig. 3. Gas Chromatogram of a Pouchong Tea (Wu Yi) Aroma Condensate Prepared by Steam Distillation under Reduced Pressure.

Column liquid phase, OV-1.

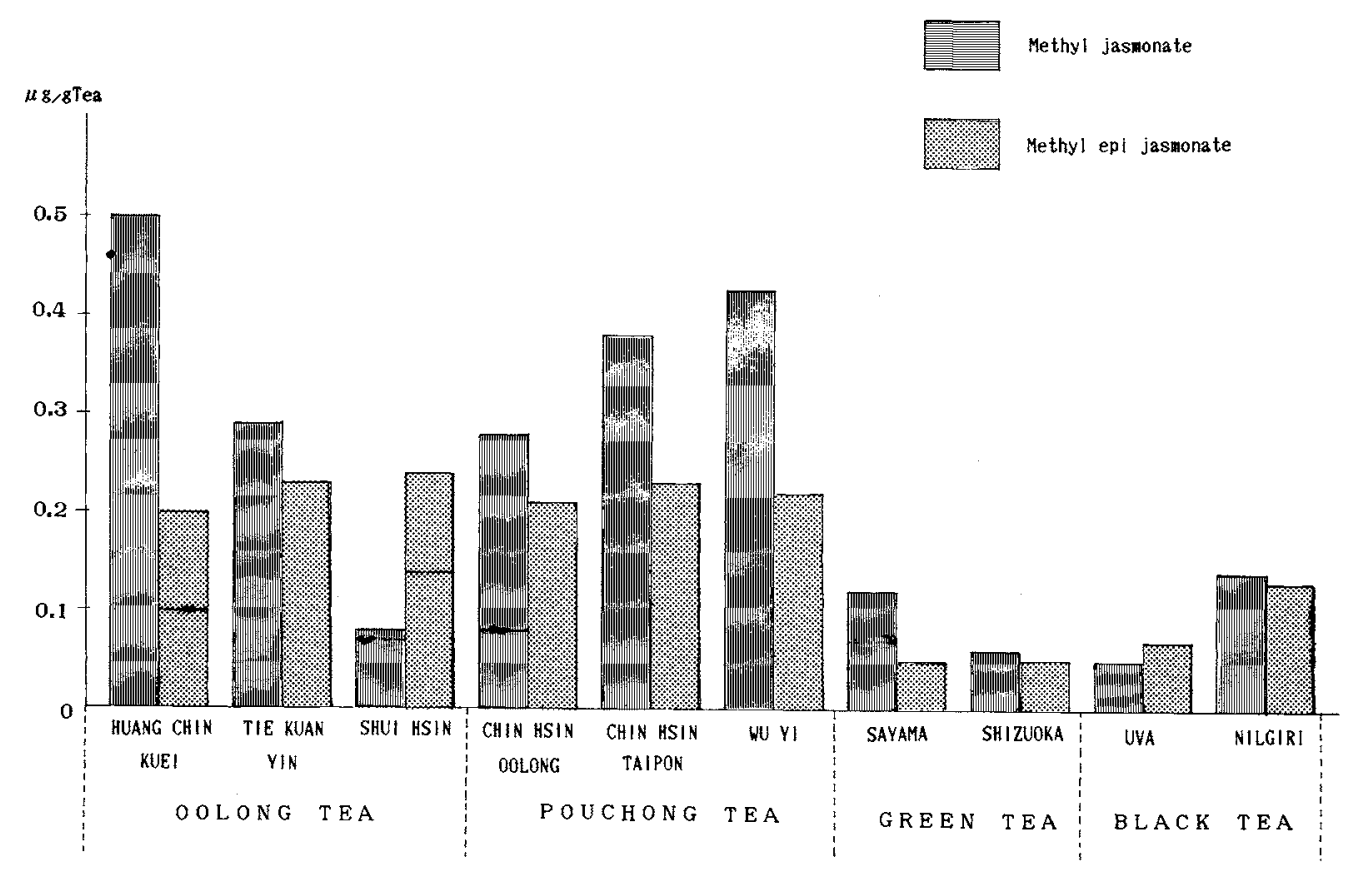

FIG. 4. Concentrations of methyl Jasmonate and Methyl Epijasmonate in Various Types of Tea. 
butions of I and II to the natural aroma.

\section{Contents of I and II in Different Teas}

Three types of oolong teas, three types of pouchong teas, two typical green teas and two high-grade black teas were steam distilled under reduced pressure. All procedures were performed at below $50^{\circ} \mathrm{C}$ and the yield of each aroma concentrate was calculated from the weight of the crude aroma concentrate by subtracting the residual amount of solvent, appearing as a GC peak. The results are summarized in Table II. The yields of the nonfermented, semi-fermented and fermented teas are in good agreement with those reported for other tea samples previously. The GC peaks of I and II were identified by mass chromatography under the same experimental conditions as previously described. The contents of $\mathbf{I}$ and II in each tea were calculated from the yield of the aroma concentrate and the relative peak areas of I and II on GC (Fig. 3). The concentrations of $\mathbf{I}$ and $\mathbf{I I}$ in dry tea products are compared as a histogram in Fig. 4, which indicates contents of II below $0.5 \mathrm{ppb}$; however, Acree et al. ${ }^{4)}$ reported threshold values for $( \pm)-I I$ and $(+)$-II of $13 \mathrm{ng} / \mathrm{ml}$ and $3 \mathrm{ng} / \mathrm{ml}$, respectively. This implies that the concentration of II in a tea is enough to give a characteristic aroma to a hot water extract; on the other hand, even the highest content of I (1.1 ppb in the case of chin hsin taipon) does not effect the characteristic aroma of a tea because of its threshold value. A characteristic feature of this histogram is that the semifermented teas have almost the same amount of II in spite of the varying contents of $\mathbf{I}$, and that this amount of II is much higher than that in green or black teas. These results conclusively support our claim that the isomerization of II to $\mathbf{I}$ is negligible with respect to the contribution of II to tea aroma, and that the contribution of $\mathbf{I I}$ is more important to the aroma of semi-fermented teas than it is to that of green and black teas.

However, the behavior of methyl epijasmonate during the separation procedure and gas chromatography suggests that we must pay much more attention to the experimental conditions when analyzing this unstable aroma compound.

Acknowledgments. We wish to thank Dr. Warita of Hasegawa Perfumery Co. for providing the standard methyl epijasmonate, and Dr. W. T.-F. Chiu of the Taiwan Tea Experimental Station for the gift of the pouchong tea samples. We also express our gratitude to Professor R. Nishida of Kyoto University for his helpful advice and suggestions.

\section{REFERENCES}

1) T. Yamanishi, M. Kosuge, Y. Tokitomo and R. Maeda, Agric. Biol. Chem., 44, 2139 (1980).

2) Y. Tokitomo, M. Ikegami, T. Yamanishi, I.-M. Juan and W. T. F. Chiew, Agric. Biol. Chem., 48, 87 (1984).

3) A. Kobayashi, K. Tachiyama, M. Kawakami, T. Yamanishi, I.-M. Juan and W. T. F. Chiew, Agric. Biol. Chem., 49, 1655 (1985).

4) T. E. Acree, R. Nishida and H. Fukami, J. Agric. Food Chem., 33, 425 (1985).

5) T. Kitahara, K. Hamaguchi, Y. Warita, Y. Takagi and K. Mori, Agric. Biol. Chem., 50, 1867 (1986).

6) G. B. Nickerson and S. T. Likens, J. Chromatogr., 21, 1 (1966).

7) T. Yamanishi, M. Nose and Y. Nakatani, Agric. Biol. Chem., 34, 599 (1970). 